\title{
Illness Perceptions of Addiction and Substance Use Patterns among Psychology Students
}

\author{
Astri Parawita Ayu ${ }^{1,2,{ }^{*}}$ Cor A J De Jong ${ }^{2}$, Lucas Pinxten ${ }^{2}$ and Arnt F A Schellekens ${ }^{1,3}$ \\ ${ }^{1}$ Department of Psychiatry and Human Behavior, School of Medicine Atma Jaya Catholic University of Indonesia, Jakarta, Indonesia \\ ${ }^{2}$ Nijmegen Institute for Scientist Practitioners in Addiction (NISPA), Radboud University, Nijmegen, the Netherlands \\ ${ }^{3}$ Department of Psychiatry, Donders Institute for Brain, Cognition and Behavior, Radboud University Medical Centre, Nijmegen, the Netherlands
}

*Corresponding author: Astri Parawita Ayu, Radboud University/ACSW NISPA Postbus 6909, 6503 GK Nijmegen, the Netherlands, Tel: +31 24 3611150; E-mail: a.ayu@psych.ru.nl

Received date: February 10, 2016, Accepted date: February 22, 2016, Published date: February 26, 2016

Copyright: $\odot 2016$ Ayu AP, et al. This is an open-access article distributed under the terms of the Creative Commons Attribution License, which permits unrestricted use, distribution, and reproduction in any medium, provided the original author and source are credited.

\begin{abstract}
Background: Negative attitudes towards patients with substance use disorders (SUDs) are common among psychologists. Perceptions of addiction might affect professionals' attitudes towards patients. Personal substance use is associated with perceptions.

Objective: To explore perceptions of addiction among psychology students in relation with their substances use.

Methods: Third-year psychology students $(\mathrm{N}=306)$ participated in this cross-sectional survey. The IPQ-A was used to evaluate perceptions of addiction. Substance use was self-reported with a standardized questionnaire. Differences in perceptions were analysed between students who use substances and do not use. Correlation between perceptions and substance use was explored.

Results: The commonly used substances were alcohol (89\%), nicotine $(21 \%)$ and cannabis $(11 \%)$. Students who use substances perceived addiction as more controllable $(p=0.03)$ and understandable $(p=<0.01)$. Nicotine use correlated with the perception that addiction is understandable.

Conclusions: Substance use is common among psychology students and that they perceive addiction as a condition with severe consequences and as emotionally stressful. The use of psychoactive substances was associated with the perceptions that addiction is controllable and understandable. Future studies need to explore how training can influence illness perceptions and how substance use among these students relates to their future attitude towards patients with SUD/addiction.
\end{abstract}

Keywords: Perception; Addiction; Substance use; Psychology student

\section{Introduction}

Among health professionals, including psychologist, negative attitudes towards patients with substance use disorders (SUDs) are common $[1,2]$. Attitudes towards SUD patients have been associated with health professionals' perceptions of addiction [2,3]. For example, concept that addiction is a bad habit and worth to be punished is associated with refusal to treat patients with addiction. On the other hand, belief that addiction can be treated successfully was related with more positive regards.

Other factors that have related with professional attitudes towards SUD patients are lack of knowledge concerning addiction and personal experiences with substance use among health professionals $[1,2,4]$. It is well known that training in addiction and SUD topics is very effective in improving knowledge and attitudes in students in professional education, such as medicine, psychology and nursing [5-8].

Unfortunately, there are also indications that without proper training, attitudes towards patients with SUDs deteriorate during university training, for example in medical school [9]. Psychologist is one of the health professionals that might meet people with SUDs in their work. Therefore, it is of crucial importance to explore substance use and perceptions concerning addiction in psychology students when they are still in training, in order to develop and implement targeted training programs.

Previous studies indicated a relationship between risk perception and psychoactive substances use. For example, the perception that limiting alcohol consumption benefits health, correlates negatively with alcohol intake among university students [10]. Among adolescents in the Netherlands perceptions on the risk to become nicotine addicted predicted abstinence of cigarette smoking [11].

Moreover, reasons to abstain from taking alcohol or drugs among university students are the perception that it will result in unwanted reduced control over emotions and behaviour, and a perceived lack of benefits of substance use [12]. The perception that substance use is harmful and potentially addictive is indeed one of the most relevant factors affecting youth substance use [13]. Change in risk perception is a predictor for changes in substance use [14]. 
Page 2 of 6

\section{Methods}

\section{Design}

This is a cross-sectional study to evaluate psychology students illness perception of addiction in relation with their substance use.

\section{Participants}

Participants were third year bachelor students from the school of psychology faculty of social sciences Radboud University, Nijmegen, The Netherlands $(\mathrm{N}=308)$ that participated in an addiction-training block. The ethics committee faculty of social sciences Radboud University has granted an ethical approval for this study. There were 55 (17.9\%) male and 253 (82.1\%) female students participated. The mean age of the respondents was 22.4 for males and 21.6 for females $(\mathrm{F}=2.53$ $\mathrm{p}=0.005)$.

\section{Measurements}

\section{Illness perception questionnaire revised version for addiction (IPQ-A)}

The IPQ-A is based on the self-regulation theory from Leventhal [18] and consists of three sections [19]. The first section explores which symptoms are associated with addiction and consist of a list of 14 symptoms. The second part consists of 38 questions focusing on perceptions of addiction, like "The illness will last a short time". The perceptions section is divided in seven subscales: timeline chronic (addiction is a chronic condition), consequences (addiction has severe consequences), personal control (patient can control addiction), treatment control (treatment can control addiction), illness coherence (I can understand addiction), timeline cyclical (addiction is a cyclical condition), and emotional representation (addiction is emotionally stressful).

The third section explores the respondents' attributions of addiction, and consists of 18 questions on possible causes of addiction. This section has four subscales: psychological attribution (addiction is caused by psychological factors), risk factor attribution (addiction is caused by specific risk factors, like heritability), immunity attribution (addiction is caused by immunological factors), and accident and chance attribution (addiction happens by chance). All questions are answered on a 5-point Likert scale: strongly disagree, disagree, neither agree nor disagree, agree, and strongly agree.

The IPQ has good psychometric properties, including acceptable test-retest reliability (0.46-0.88) among rheumatoid arthritis and renal dialysis patients [16].

\section{Psychoactive substance use report}

To evaluate the history of psychoactive substance use among the respondents, we used a questionnaire listing the most commonly used substances, including coffee, tea, alcohol, nicotine, cannabis, opiates, cocaine, stimulants, ecstasy, GHB and ketamine. The questionnaire evaluates the total days of use over the last 30 days, the amount of substance being used each time, and the total years of use of each substance, inline with the CIDI version 2.1 [20,21].

\section{Procedure}

All participants were asked to fill in the questionnaires in the classroom before the first lecture of the addiction block, in order to avoid any effect of training on their perceptions. The questionnaires reflect their perceptions towards addiction and their own substance use patterns. The duration to fill in the questionnaires was around $15-$ 20 minutes. There was no obligation to fill in the questionnaires and they were asked to fill in the questionnaire annonymously.

They also were asked for consent to use the data anonymously for research. The students received feedback as a group about their perceptions towards addiction and substance use patterns. The questionnaires were delivered twice to 2 groups of students (in 2013 and 2014). In 2013, 144 participants handed in the questionnaires, of which five were incomplete. In 2014, 169 completed questionnaires were handed in. Finally, 308 questionnaires could be included in the analyses.

\section{Analyses}

The data were analysed with SPSS version 19.0. Descriptive statistics (mean/percentage, standard deviation) were used to describe the history of substance use. Based on the substance use history the group was divided into students who use and do not use drugs. Since coffee and tea are not listed as substances of abuse (Diagnostic Statistical Manual of Mental Disorder, DSM-5) [22], the user-group consisted of students that used nicotine, alcohol, cannabis, cocaine, stimulant, ecstasy, GHB, sedative, and ketamine.

For the IPQ-A, the scores on the subscales of the perceptions and attributions sections were computed according to the algorithm of the IPQ-R [16]. Means and standard deviations for each subscale were calculated for group of students who use and do not use drugs separately. The first section of addiction symptoms was kept out of the analyses, because this part of the questionnaire refers to experienced symptoms as a patient, which is not applicable here.

Differences in illness perceptions between the group of students who use and do not use drugs were analysed using multivariate analyses of variance with perceptions as dependent variable, history of substance use as independent variable, and gender as covariate.

To further explore the association between substances use patterns and perceptions of addiction, we calculated the Pearson correlation between IPQ subscale scores that are significantly different between students who use and do not use drugs with self-reported substance use (days of use over past 30 days, amount of use, and years of use) per substance (with a minimum of ten subjects per group). Since coffee and tea are not listed as substances of abuse (Diagnostic Statistical Manual of Mental Disorder, DSM-5) [22] these were kept out of the correlation analyses.

\section{Results}

\section{Drug use among psychology students}

The most commonly used substances by psychology students over the last 30 days are presented in Table 1 . These were tea (male $=81.8 \%$, female $=95.3 \%)$, alcohol (male $=92.7 \%$, female $=88.1 \%)$, coffee $($ male $=72.7 \%$, female $=65.2 \%)$, nicotine $($ male $=29.1 \%$, female $=19.8 \%)$, and cannabis $($ male $=25.5 \%$, female $=7.5 \%$ ). Few participants reported 
Citation: Ayu AP, De Jong CAJ, Pinxten L, Schellekens AFA (2016) Illness Perceptions of Addiction and Substance Use Patterns among

Page 3 of 6

the use of sedatives $($ male $=1.8 \%$, female $=4.3 \%$ ), ecstasy $($ male $=1.8 \%$, female $=2.4 \%)$, stimulants $\quad($ male $=7.3 \%$, female $=0.8 \%)$, cocaine (male $=1.8 \%$, female $=0.8 \%)$, GHB (male $=1.8 \%)$, and ketamine (female $=0.4 \%$ ). In general, there was a trend that more male students used substances compared to females (male $=96.4 \%$, female $=88.9 \%$, $\mathrm{p}=0.092$ ).

\begin{tabular}{|c|c|c|c|c|}
\hline & Male & Female & & t-value(df) \\
\hline \multirow[t]{2}{*}{ Substance use } & $(n=55)$ & $(n=253)$ & $\mathrm{p}$ & \\
\hline & Mean & Mean & & \\
\hline Coffee (\%) & 72.7 & 65.2 & 0.29 & $x^{2}(1)=1.145$ \\
\hline days of use & $19(11.0)$ & $18.2(10.7)$ & 0.69 & $0.403(203)$ \\
\hline amount of use & $1.7(0.7)$ & $1.7(1.1)$ & 0.8 & $-0.258(203)$ \\
\hline years of use & $4.8(3.0)$ & $4.1(2.9)$ & 0.18 & $1.333(203)$ \\
\hline Tea (\%) & 81.8 & 95.3 & $<0.01^{*}$ & $x^{2}(1)=12.320$ \\
\hline days of use & $15.3(9.9)$ & $20(10.3)$ & $0.01^{*}$ & $-2.811(284)$ \\
\hline amount of use & $1.9(0.9)$ & $2.3(1.6)$ & 0.06 & $-1.873(284)$ \\
\hline years of use & $7.1(6.2)$ & $8.7(5.4)$ & 0.07 & $-1.837(284)$ \\
\hline Alcohol (\%) & 92.7 & 88.1 & 0.33 & $x^{2}(1)=0.967$ \\
\hline days of use & $7.4(6.7)$ & $5.9(4.1)$ & 0.14 & $1.512(58.772)$ \\
\hline amount of use & $4.9(3.6)$ & $4.0(2.3)$ & 0.1 & $1.696(59.992)$ \\
\hline years of use & $5.7(2.3)$ & $5.2(2.4)$ & 0.19 & $1.303(272)$ \\
\hline Nicotine (\%) & 29.1 & 19.8 & 0.13 & $x^{2}(1)=2.335$ \\
\hline days of use & $13.3(13.8)$ & $12.9(12.0)$ & 0.92 & $0.100(64)$ \\
\hline amount of use & $4.7(4.1)$ & $4.4(4.2)$ & 0.82 & $0.224(64)$ \\
\hline years of use & $4.3(3.6)$ & $3.6(2.7)$ & 0.4 & $0.851(64)$ \\
\hline Cannabis (\%) & 25.5 & 7.5 & $<0.01^{*}$ & $X^{2}(1)=15.208$ \\
\hline days of use & $7.9(10.3)$ & $3.9(6.8)$ & 0.19 & $1.354(31)$ \\
\hline amount of use & $1.5(0.8)$ & $1.2(0.6)$ & 0.13 & $1.551(31)$ \\
\hline years of use & $3.9(3.2)$ & $2.3(1.9)$ & 0.11 & $1.671(19.613)$ \\
\hline Cocaine (\%) & 1.8 & 0.8 & 0.48 & $x^{2}(1)=0.495$ \\
\hline days of use & 1 & $1.5(0.7)$ & - & $-0.577(1)$ \\
\hline amount of use & 1 & $1.5(0.7)$ & - & $-0.577(1)$ \\
\hline years of use & 1 & $1(1.4)$ & - & $0.000(1)$ \\
\hline Stimulant (\%) & 7.3 & 0.8 & $<0.01^{*}$ & $x^{2}(1)=9.939$ \\
\hline days of use & $7.3(7.3)$ & $2(1.4)$ & 0.25 & $1.384(3.408)$ \\
\hline amount of use & 1 & 1 & - & - \\
\hline years of use & $3.8(3.9)$ & $1(1.4)$ & 0.28 & $1.265(3.969)$ \\
\hline Ecstasy (\%) & 1.8 & 2.4 & 0.8 & $x^{2}(1)=0.062$ \\
\hline days of use & 1 & $1.2(0.4)$ & - & $-0.378(5)$ \\
\hline amount of use & 2 & $0.8(0.3)$ & - & $4.183(5)$ \\
\hline
\end{tabular}

\begin{tabular}{|l|l|l|l|l|}
\hline years of use & 1 & $1.4(1.0)$ & - & $-0.378(5)$ \\
\hline GHB (\%) & 1.8 & 0 & $0.03^{*}$ & $\mathrm{X}^{2}(1)=4.615$ \\
\hline days of use & 1 & - & - & - \\
\hline amount of use & 3 & - & - & - \\
\hline years of use & 0 & - & - & - \\
\hline Sedative (\%) & 1.8 & 4.3 & 0.38 & $\mathrm{X}^{2}(1)=0.772$ \\
\hline days of use & 20 & $11.5(13.1)$ & - & $0.627(10)$ \\
\hline amount of use & 2 & $1.4(0.7)$ & - & $0.904(10)$ \\
\hline years of use & 3 & $2.1(2.9)$ & - & $0.319(10)$ \\
\hline Ketamine (\%) & 0 & 0.4 & 0.64 & $\mathrm{X}^{2}(1)=0.218$ \\
\hline days of use & - & 0 & - & - \\
\hline amount of use & - & 0 & - & - \\
\hline years of use & - & 1 & - & - \\
\hline
\end{tabular}

Table 1: Population description.

\section{Perception and attribution of addiction among psychology students}

In general, psychology students recognize that addiction has severe consequences (students who use substances $=4.5, \mathrm{SD}=0.4$; students who do not use substances $=4.4, \mathrm{SD}=0.4$ ) and emotionally stressful (students who use substances $=4.3, \mathrm{SD}=0.6$; students who do not use substances $=4.3, \mathrm{SD}=0.5$ ).

Moreover, they also think that addiction is a condition that is understandable (students who use substances $=4.1, \mathrm{SD}=0.6$; students who do not use substances $=3.9, \mathrm{SD}=0.6$ ), chronic (students who use substances $=3.9, \mathrm{SD}=0.5$; students who do not use substances $=3.9$, $\mathrm{SD}=0.5$ ) and controllable (students who use substances $=3.9, \mathrm{SD}=0.5$; students who do not use substances $=3.8, \mathrm{SD}=0.5$ ). They also attribute addiction to psychological and general risk factors (students who use substances $=4.3, \mathrm{SD}=0.4$; students who do not use substances $=4.3$, $\mathrm{SD}=0.4$ and students who use substances $=3.6, \mathrm{SD}=0.4$; students who do not use substances $=3.7, \mathrm{SD}=0.4$, respectively).

\section{Differences in perceptions and attributions of addiction between students who use substances and do not use substances}

Differences in perceptions and attributions of addiction between students who use and do not use substances are summarized in Table 2. We observed the difference of perception between students who use and do not use substances $(\mathrm{F}(11,295)=2.859, \mathrm{p}<.01)$.

Students who regularly use substances believed more that addiction can be controlled and that they understand addiction, compared to those who do not use substances $(\mathrm{F}(1,305)=4.696, \mathrm{p}=0.03$; $\mathrm{F}(1,305)=10.041, \mathrm{p}=<0.01$ respectively). There were no differences between the students who use and do not use substances on any of the attribution subscales. 


\begin{tabular}{|c|c|c|c|c|c|c|}
\hline & $\begin{array}{l}\text { Use substances } \\
(n=91) \text { mean }\end{array}$ & SD & $\begin{array}{l}\text { Do not use } \\
\text { substances } \\
(\mathrm{n}=217) \\
\text { mean }\end{array}$ & SD & $F(1,305)$ & $\mathbf{P}$ \\
\hline \multicolumn{7}{|l|}{ Perception } \\
\hline $\begin{array}{l}\text { Addiction is } \\
\text { a chronic } \\
\text { condition }\end{array}$ & 3.9 & 0.5 & 3.9 & 0.5 & 0 & 0.98 \\
\hline $\begin{array}{l}\text { Addiction } \\
\text { has severe } \\
\text { consequenc } \\
\text { es }\end{array}$ & 4.5 & 0.4 & 4.4 & 0.4 & 0.474 & 0.49 \\
\hline $\begin{array}{l}\text { Patient can } \\
\text { control } \\
\text { addiction }\end{array}$ & 3.9 & 0.5 & 3.8 & 0.5 & 4.696 & $0.03^{*}$ \\
\hline $\begin{array}{l}\text { Treatment } \\
\text { can control } \\
\text { addiction }\end{array}$ & 3.9 & 0.4 & 3.8 & 0.4 & 2.617 & 0.11 \\
\hline $\begin{array}{l}\text { I can } \\
\text { understand } \\
\text { addiction }\end{array}$ & 4.1 & 0.6 & 3.9 & 0.6 & 10.041 & $\begin{array}{l}<0.01 \\
*\end{array}$ \\
\hline $\begin{array}{l}\text { Addiction is } \\
\text { a cyclic } \\
\text { condition }\end{array}$ & 3 & 0.6 & 3.1 & 0.6 & 1.169 & 0.28 \\
\hline $\begin{array}{l}\text { Addiction is } \\
\text { emotionally } \\
\text { stressful }\end{array}$ & 4.3 & 0.6 & 4.3 & 0.5 & 0.004 & 0.95 \\
\hline \multicolumn{7}{|l|}{ Attribution } \\
\hline $\begin{array}{l}\text { Psychologic } \\
\text { al attribution }\end{array}$ & 4.3 & 0.4 & 4.3 & 0.4 & 3.559 & 0.06 \\
\hline Risk factor & 3.6 & 0.4 & 3.7 & 0.4 & 3.208 & 0.07 \\
\hline Immunity & 2.3 & 0.8 & 2.2 & 0.7 & 0.004 & 0.95 \\
\hline $\begin{array}{l}\text { Accident } \\
\text { and chance }\end{array}$ & 3.1 & 0.7 & 2.9 & 0.8 & 2.701 & 0.1 \\
\hline
\end{tabular}

Table 2: Perception and attribution of addiction among participants.

Relationship perceptions and attributions of addiction with substance use patterns. Among students who use substances the correlation between perceptions of addiction that are significantly different with those who do not use substances and substance use patterns were explored. The perceptions are 'patient can control addiction' and 'I can understand addiction'. The perception that addiction is understandable was related to higher nicotine use (days of use over past 30 days: $\mathrm{r}=0.29, \mathrm{p}=0.02$; amount of use $\mathrm{r}=0.32, \mathrm{p}=0.01$; years of use $\mathrm{r}=0.29, \mathrm{p}=0.02$ ). The perception that patient can control addiction was not related with any substance use.

\section{Discussion}

The current study investigated the relationship between illness perceptions of addiction among psychology students and personal experience with substance use. The results show that substance use is common among these students and that they perceive addiction as a condition with severe consequences and as emotionally stressful. The use of psychoactive substances was associated with the perceptions that addiction is controllable and understandable.
Psychology students have the perception that addiction has severe consequences and is emotionally stressful. Moreover, they perceive addiction as an understandable condition that is both chronic and controllable. They also believe that psychological and risk factors are important causes of addiction. Previous study reported that addiction treatment providers in United Kingdom believed that addiction is a way of coping with life [23]. That belief includes items similar as controllable and psychological subscales of IPQ, for example: alcoholics and drug addicts can learn to moderate their drinking or cut down their own drug use and people become addicted to drugs/ alcohol when life is going badly for them [24].

It is unclear how perceptions of addiction among health professionals evolve over time, and how training can influence these perceptions. It has been shown that reflective teaching methods can effectively improve attitudes towards and perceptions of addicted patients among medical doctors [5]. Similarly, few studies explored the effect of interventions aiming to influence illness perceptions among patients [25]. In patients with asthma and myocardial infarction education programs resulted in increased belief that their condition can be controlled, which had positive effects, for example on treatment adherence [26] and functional outcome [27]. How training can influence illness perceptions among health professionals, and how this affects their clinical work remains to be investigated. Nonetheless, the IPQ-A might be a useful instrument to support reflective teaching methods, or to evaluate the effect of training on perceptions of addiction among students.

Students who regularly use substances believed more that addiction can be controlled and that they understand addiction, compared to students who do not use substances. Moreover, among students who use nicotine, higher levels of nicotine use were associated with the perception that addiction is understandable (moderate correlation). These findings are in line with previous findings that medical students with more positive expectancies of the effects of substance use more regularly use alcohol or other psychoactive substances, compared to those with more negative expectancies of the effects of substance use [28]. More positive expectancies on the effects of substance use and illness perceptions of addiction might therefore both relate to increased levels of substance use among students. This suggests that expectancies on the effects of substance use and illness perceptions of addiction could be related. This is of particular relevance in the context of students in training for health professionals, since these students will be future therapists. Indeed, health care professionals with regular use of psychoactive substances showed more negative attitude compared to their colleagues who do not use psychoactive substances [4]. How substance use among psychology students relates to their future attitude towards patients with SUD/addiction remains to be investigated.

It could be speculated that the observation that the relationship between perceptions of addiction and the use of psychoactive substances was mainly observed in nicotine users is related to the addictive potential of nicotine. Nicotine is considered as a highly addictive substance. Though nicotine use is accepted in many societies, regular nicotine use should in fact often be considered as an addiction [29]. It can be expected that regular nicotine users more often display addictive behaviour as compared to those regularly using alcohol or cannabis. This may well explain the observed relationship between level of nicotine use and perception that addiction is understandable, which was not observed for other substances. 
Page 5 of 6

The level of substance use among psychology students observed here is comparable with substance use patterns in the general population in the Netherlands (mainly alcohol: $88.1-92.7 \%$, coffee: 65.2-72.7\%, nicotine: $19.8-29.1 \%$, and cannabis: $7.5-25.5 \%)$ and previous studies on the use of psychoactive substances by Dutch dental students (alcohol use 95\%; tobacco 42\%; marijuana 24\%) [30]. Patterns of substance use among Dutch psychology students are also comparable to other countries. For instance, in the USA and Brazil the most commonly used drugs among college students are also alcohol, cannabis, and nicotine [31,32].

In line with previous studies male students tended to report more substance use compared to females $[28,31,33]$. It has been shown that among male students the number of students who drink alcohol increases during their college years, but remains stable among females [33]. Since we included third year students, this may explain the increased levels of substance use among males. In contrast, females more often used sedatives compared to male psychology students. Among medical students and medical doctors the use of tranquilizers was also higher among females than among males $[32,34]$.

The results of the current study should be seen in the light of its limitations. First, the IPQ-R is a well-validated instrument, designed to assess illness perceptions in patients. It has been used worldwide to evaluate patients' perceptions towards their illness in a variety of conditions, including chronic fatigue syndrome, asthma and schizophrenia $[25,26]$. We applied a novel approach, using the IPQ-R in a group of undergraduate students to assess their perception of addiction, a condition most of them will not have themselves. Future studies should confirm the validity and reliability of the IPQ- $R$ when applied in healthy controls. Second, these findings may not be generalizable to students of other faculties or other countries. Finally, little is known about illness perceptions among health professionals and how these affect the therapeutic relationship. This is a potentially very relevant area of research, since illness perceptions can vary widely among health professionals and the quality of the therapeutic relationship is very relevant in the context of addiction.

Taken together, our findings show that perceptions of addiction may be related to the students' substance use. To what extent perceptions and attributions of addiction evolve over time, can be influenced by training and how they relate to the attitude towards addicted patients remains to be investigated. These issues should be addressed in future studies using the IPQ-R. The IPQ-R seems to be an instrument that could be used for training purposes, by supporting reflective teaching methods and as a tool to evaluate the effect of addiction training on illness perceptions of addiction.

\section{Acknowledgement}

The authors wish to thank W.J. Burk, PhD as our consultant statistic and the psychology student of the faculty of social science Radboud University as our respondent.

\section{Funding}

This work is supported by the Indonesian Directorate General of Resources for Research, Technology and Higher Education Ministry of Research, Technology, and Higher Education, no: 94.19/E4.4/2014 to Astri Parawita Ayu. The funder had no role in study design, data collection and analysis, decision to publish, and preparation of the manuscript.

\section{References}

1. Gilchrist G, Moskalewicz J, Slezakova S, Okruhlica L, Torrens M, et al. (2011) Staff regard towards working with substance users: a European multi-centre study. Addiction 106: 1114-1125.

2. Boekel LCV, Brouwers EPM, Weeghel JV, Garretsen HFL (2014) Healthcare professionals' regard towards working with patients with substance use disorders: Comparison of primary care, general psychiatry and specialist addiction services. Drug Alcohol Depend 134: 92-98.

3. Tang YL, Wiste A, Mao PX, Hou YZ (2005) Attitudes, knowledge, and perceptions of Chinese doctors toward drug abuse. J Subst Abuse Treat 29: 215-220.

4. Raistrick D, Russell D, Tober G, Tindale A (2008) A survey of substance use by health care professionals and their attitudes to substance misuse. Journal of Substance Use 13: 57-69.

5. Ayu AP, Schellekens AF, Iskandar S, Pinxten L, De Jong CA (2015) Effectiveness and Organization of Addiction Medicine Training Across the Globe. Eur Addict Res 21: 223-239.

6. Aanavi MP, Taube DO, Ja DY, Duran EF (1999) The status of psychologists' training about and treatment of substance-abusing clients. J Psychoactive Drugs 31: 441-444.

7. Martinez RJ, Murphy-Parker D (2003) Examining the relationship of addiction education and beliefs of nursing students toward persons with alcohol problems. Arch Psychiatr Nurs 17: 156-164.

8. Stein JB (2003) Attitude of social work students about substance abuse: Can a brief educational program make a difference? Journal of Social Work Practice in the Addictions 3: 77-90.

9. Cape G, Hannah A, Sellman D (2006) A longitudinal evaluation of medical student knowledge, skills and attitudes to alcohol and drugs. Addiction 101: 841-849.

10. Dantzer C, Wardle J, Fuller R, Pampalone SZ, Steptoe A (2006) International study of heavy drinking: attitudes and sociodemographic factors in university students. J Am Coll Health 55: 83-89.

11. Ausems M, Mesters I, van Breukelen G, De Vries H (2003) Do Dutch 11-12 years olds who never smoke, smoke experimentally or smoke regularly have different demographic backgrounds and perceptions of smoking? Eur J Public Health 13: 160-167.

12. Rosenberg H, Bonar EE, Pavlick M, Jones LD, Hoffmann E, et al. (2012) Associations Between University Students' Reported Reasons for Abstinence From Illicit Substance and Type of Drug. J Coll Stud Dev 53: 91-105.

13. Arens CR, White TL, Massengill N (2014) Attitudinal factors protective against youth smoking: an integrative review. J Nurs Scholarsh 46: 167-175.

14. Grevenstein D1, Nagy E, Kroeninger-Jungaberle H (2015) Development of risk perception and substance use of tobacco, alcohol and cannabis among adolescents and emerging adults: evidence of directional influences. Subst Use Misuse 50: 376-386.

15. Mo PKH, Lau JTF, Cheng KM, Mak WWS, Gu J, et al. (2015) Investigating the factor structure of the Illness Perception QuestionnaireRevised for substance dependence among injecting drug users in China. Drug Alcohol Depend 148:195-202.

16. Moss-Morris R, Weinman J, Petrie K, Horne R, Cameron L, et al. (2002) The revised illness perception questionnaire (IPQ-R). Psychol Health 17: $1-16$.

17. http://www.who.int/substance_abuse/research_tools/translation/en/ index.html

18. Leventhal H, Leventhal EA, Contrada RJ (1998) Self-regulation, health, and behavior: A perceptual-cognitive approach. Psychol Health 13: 717-733.

19. Weinman J, Petrie KJ, Moss-morris R, Horne R (1996) The illness perception questionnaire: A new method for assessing the cognitive representation of illness. Psychol Health 11: 431-455.

20. Schippers GM, Broekman T, Buchholz A, Cox WM (2011) Measurements in the Addiction for Triage and Evaluation (MATE 2.1.): Manual and 
Citation: Ayu AP, De Jong CAJ, Pinxten L, Schellekens AFA (2016) Illness Perceptions of Addiction and Substance Use Patterns among Psychology Students. J Child Adolesc Behav 4: 279. doi:10.4172/2375-4494.1000279

Page 6 of 6

protocol. English Edition: WM Cox, Bêta Boeken, Nijmegen, the Netherlands.

21. (1997) Composite International Diagnostic Interview (CIDI) core version 2.1. World Health Organization, Geneva.

22. (2013) Substance-Related and Addictive Disorders. In Diagnostic and Statistical Manual of Mental Disorder: DSM-5. American Psychiatric Association, Arlington.

23. Russell C, Davies JB, Hunter SC (2011) Predictors of addiction treatment providers' beliefs in the disease and choice models of addiction. J Subst Abuse Treat 40: 150-164.

24. Schaler JA (1995) The Addiction Belief Scale. Int J Addict 30: 117-134.

25. Petrie KJ, Jago LA, Devcich DA (2007) The role of illness perceptions in patients with medical conditions. Curr Opin Psychiatry 20: 163-167.

26. Kaptein AA1, Klok T, Moss-Morris R, Brand PL (2010) Illness perceptions: impact on self-management and control in asthma. Curr Opin Allergy Clin Immunol 10: 194-199.

27. Petrie KJ, Cameron LD, Ellis CJ, Buick D, Weinman J (2002) Changing illness perceptions after myocardial infarction: An early intervention randomized controlled trial. Psychosom Med 64: 580-586.

28. James BO, Omoaregba JO (2013) Nigerian medical students' opinions about individuals who use and abuse psychoactive substances. Subst Abuse 7: 109-116.
29. Baker TB, Breslau N, Covey L, Shiffman S (2012) DSM criteria for tobacco use disorder and tobacco withdrawal: a critique and proposed revisions for DSM-5. Addiction 107: 263-275.

30. Plasschaert AJ, Hoogstraten J, van Emmerik BJ, Webster DB, Clayton RR (2001) Substance use among Dutch dental students. Community Dent Oral Epidemiol 29: 48-54.

31. Johnston LD, O'Malley PM, Bachman JG, Schulenberg JE (2012) Monitoring the Future national survey results on drug use, 1975 - 2011: College students and adults ages 19-50 In Institute for Social Research, The University of Michigan Ann Arbor.

32. Da Silveira DX, Rosa-Oliveira L, Di Pietro M, Niel M, Doering-Silveira E, et al. (2008) Evolutional pattern of drug use by medical students. Addict Behav 33: 490-495.

33. Boland M, Fitzpatrick P, Scallan E, Daly L, Herity B, et al. (2006) Trends in medical student use of tobacco, alcohol and drugs in an Irish university, 1973-2002. Drug Alcohol Depend 85: 123-128.

34. Wunsch MJ, Knisely JS, Cropsey KL, Campbell ED, Schnoll SH (2007) Women physicians and addiction. J Addict Dis 26: 35-43. 